Please do not remove this page

RMIT

UNIVERSITY

\title{
Tensile properties of carbon fibres and carbon fibre-polymer composites in fire
}

Feih, Stefanie; Mouritz, Adrian

https://researchrepository.rmit.edu.au/esploro/outputs/9921858365401341/filesAndLinks?institution=61RMIT_INST\&index=null

Feih, S., \& Mouritz, A. (2012). Tensile properties of carbon fibres and carbon fibre-polymer composites in fire. Composites Part A: Applied Science and Manufacturing, 43(5), 765-772.

https://doi.org/10.1016/j.compositesa.2011.06.016

Document Version: Accepted Manuscript

Published Version: https://doi.org/10.1016/j.compositesa.2011.06.016

Repository homepage: https://researchrepository.rmit.edu.au

(c) 2011 Elsevier Ltd. All rights reserved

Downloaded On 2023/04/26 16:18:23 +1000

Please do not remove this page 
Thank you for downloading this document from the RMIT Research Repository.

The RMIT Research Repository is an open access database showcasing the research outputs of RMIT University researchers.

RMIT Research Repository: http://researchbank.rmit.edu.au/

\section{Citation:}

Feih, S and Mouritz, A 2012, 'Tensile properties of carbon fibres and carbon fibre-polymer composites in fire', Composites Part A: Applied Science and Manufacturing, vol. 43, no. 5, pp. 765-772.

See this record in the RMIT Research Repository at:

http://researchbank.rmit.edu.au/view/rmit:16267

Version: Accepted Manuscript

Copyright Statement: (c) 2011 Elsevier Ltd. All rights reserved

Link to Published Version:

http://dx.doi.org/10.1016/j.compositesa.2011.06.016

\section{PLEASE DO NOT REMOVE THIS PAGE}




\title{
TENSILE PROPERTIES OF CARBON FIBRES AND CARBON FIBRE-POLYMER COMPOSITES IN FIRE
}

\author{
S. Feih ${ }^{1,2}$ \& A. P. Mouritz ${ }^{1, *}$ \\ 1. School of Aerospace, Mechanical \& Manufacturing Engineering, \\ Royal Melbourne Institute of Technology, Melbourne, Victoria, 3001, Australia \\ 2. Cooperative Research Centre for Advanced Composite Structures Ltd (CRC-ACS), \\ Fishermans Bend, Victoria, 3207, Australia
}

*e-mail: adrian.mouritz@rmit.edu.au Tel.: +61 399256269

Fax: +61399256108 


\begin{abstract}
The effect of fire on the tensile properties of carbon fibres is experimentally determined to provide new insights into the tensile performance of carbon fibre-polymer composite materials during fire. Structural tests on carbon-epoxy laminate reveal that thermally-activated weakening of the fibre reinforcement is the dominant softening process which leads to failure in the event of a fire. This process is experimentally investigated by determining the reduction to the tensile properties and identifying the softening mechanism of T700 carbon fibre following exposure to simulated fires of different temperatures (up to $700^{\circ} \mathrm{C}$ ) and atmospheres (air and inert). The fibre modulus decreases with increasing temperature (above $\sim 500^{\circ} \mathrm{C}$ ) in air, which is attributed to the oxidation of the higher stiffness layer in the near-surface fibre region. The fibre modulus is not affected when heated in an inert (nitrogen) atmosphere due to the absence of surface oxidation, revealing that the stiffness loss of carbon fibre composites in fire is sensitive to the oxygen content. The tensile strength of carbon fibre is reduced by nearly $50 \%$ following exposure to temperatures over the range $400-700^{\circ} \mathrm{C}$ in an air or inert atmosphere. Unlike the fibre modulus, the reduction in fibre strength is insensitive to the oxygen content of the atmosphere during fire. The reduction in strength is possibly attributable to very small (under $\sim 100 \mathrm{~nm}$ ) flaws and removal of the sizing caused by high temperature exposure.
\end{abstract}


A long-standing concern with using fibre-polymer laminates and sandwich composites in structural applications is the low softening temperature of the polymer matrix, which may cause distortion, weakening and failure of heavily-loaded composite structures when exposed to moderate temperature fire (above $150-200^{\circ} \mathrm{C}$ ). A large body of theoretical and experimental research into the structural performance of laminates and sandwich composites in fire has been performed [e.g. 1-12]. Most research has focussed on the structural performance of fibreglass composites under compression loads, where thermal softening of the polymer matrix is the dominant process controlling mechanical integrity in fire. Feih et al. [11] have shown, however, that the structural performance of fibreglass composites under tensile loading in fire is dependent on thermal softening of both the load-bearing fibres and polymer matrix. Feih and colleagues showed that the tensile performance of fibreglass composites in fire is strongly influenced by fibre softening.

While the structural properties of fibreglass composites during fire have been studied in detail, less is known about the structural integrity of carbon fibre laminates and sandwich materials in fire and postfire [13-20]. The structural performance of carbon fibre composites during fire and post-fire can be different to fibreglass materials because the carbon reinforcement oxidises at high temperature, unlike glass fibre. The post-fire performance for glass and carbon composites has been compared by Berlin et al [20]. A small number of studies into the properties of carbon fibre composites under compression loading during fire have also been performed [18,19], where the structural integrity is dependent on matrix softening. Isothermal tensile properties at elevated temperatures were investigated [21,22]; however, the structural response of carbon fibre composites under tensile loading during fire has not been investigated, including the mechanism responsible for mechanical softening and failure. Based on previous research by the authors, it is expected that the tensile performance will mostly depend on the properties of the fibre reinforcement [11].

With the increased use of carbon fibre composites in aircraft, ships and civil infrastructure, understanding the structural performance of these materials during fire is an important safety issue. While a large amount of information is available on the high-temperature oxidation $\left(>1500^{\circ} \mathrm{C}\right)$ and mechanical properties of carbon fibres due to their application in heat resistant carbon-carbon composites, only a few investigations have been performed on their oxidation behaviour over the temperature range of most fires (typically $400-1100^{\circ} \mathrm{C}$ ) $[23,24]$. Furthermore, the effect of the atmosphere on the mechanical properties of carbon fibres is not well understood. The oxygen content of fire within an enclosed space can vary between about $8 \%$ and $21 \%$ depending on the availability of air; at oxygen levels below $8 \%$ the fire will self-extinguish. Another consideration is that the exposure of carbon fibres to oxygen changes with distance below the surface of a hot, decomposing composite, 
as shown schematically in figure 1 . Carbon fibres close to the hot surface are exposed to oxygen within the atmosphere, but below the surface the fibres are exposed to an oxygen-lean environment because the out-gassing of volatiles released during decomposition of the polymer matrix impedes the ingress of air into the decomposed (char) material. Therefore, carbon fibres at the surface (where air is present) and below the surface (where air is absent) experience different atmospheric (oxygen) conditions that may affect their mechanical properties and softening mechanism.

To investigate these issues, this paper presents an experimental study into the mechanical properties and damage mechanisms of carbon fibre and carbon fibre-epoxy composites during fire. The structural performance of a T700 carbon-epoxy laminate under combined one-sided radiant heating (which simulates the environment of fire) and tensile loading was used to assess the influence of fibre softening on the mechanical integrity in fire. The effects of temperature and atmosphere on the tensile stiffness and strength properties of T700 carbon fibre were investigated. T700 carbon was studied because of its wide-spread use in composite structures for aircraft, ship, civil infrastructure and other applications. The carbon fibres were heated within a furnace at different temperatures (up to $700^{\circ} \mathrm{C}$ ) to simulate fires which radiate different amounts of heat. The fibres were heated within air or nitrogen (inert) gas to simulate the environmental conditions where oxygen is present or absent, respectively. The damage processes responsible for softening and weakening of carbon fibres under these simulated conditions were determined using thermogravimetric analysis, scanning electron microscopy (SEM), and fractographic analysis. The research aims at providing new insights and quantitative information for the mechanical properties and damage mechanisms of carbon fibres used in composite structures during fire. Equations for modulus reduction and strength loss are presented, which can be included in currently developed structural analysis codes for carbon fibre-polymer composite materials exposed to fire.

\section{MATERIALS \& EXPERIMENTAL METHODS}

Structural tests were performed on carbon fibre-epoxy laminate under combined one-sided radiant heating and axial tensile loading. The laminate was fabricated using unidirectional T700 carbon-epoxy prepreg (VTM264; Advanced Composite Group) arranged in a [0/90] fibre pattern. The laminate was cured in an autoclave at $120^{\circ} \mathrm{C}$ and $620 \mathrm{kPa}$ for one hour. The cured laminate had a thickness of 4.3 $\mathrm{mm}$, fibre volume content of $55 \%$, and glass transition temperature of $128^{\circ} \mathrm{C}$. The tensile modulus and strength of the laminate when measured at $20^{\circ} \mathrm{C}$ was $57.5 \mathrm{GPa}$ and $790 \mathrm{MPa}$, respectively.

Flat rectangular coupons of the laminate (measuring $560 \mathrm{~mm}$ long, $50 \mathrm{~mm}$ wide, $4.3 \mathrm{~mm}$ thick) were used to determine the tensile performance of the carbon-epoxy material under combined one-sided heating and tensile loading. The laminate coupons were exposed to a constant radiant heat flux of 35 
or $50 \mathrm{~kW} / \mathrm{m}^{2}$ while under constant tensile stress. The time-to-failure of the coupon was used to assess the tensile softening and residual strength of the laminate while under simulated attack of fire. The failure mode of the cross-ply laminate was fibre-strength controlled, and all samples failed in the heated gauge section. The temperatures at the front (heated) and back (unheated) surfaces of the laminate specimens were recorded during testing using K-type thermocouples. A full description of the structural test procedure is provided by Feih et al. [11].

The effects of temperature and atmosphere on the tensile properties of carbon fibres were investigated using high-strength PAN-based T700 continuous filaments (Toray). This is the same type of fibre used in the carbon-epoxy laminate, and was selected because it is one of the most widely used grades of carbon fibre. The fibres were supplied by Sigmatex (US) with FOE sizing and average diameter of $6.7 \pm 0.3 \mu \mathrm{m}$. Carbon fibre bundles were heat-treated inside a furnace in an oxygen-rich (air) or inert (high purity nitrogen) atmosphere. No load was applied to the carbon bundles during heat treatment. The bundles were isothermally treated at constant temperature between 250 and $700^{\circ} \mathrm{C}$ for up to four hours. After heating, the bundles were cooled to room temperature and then the tensile properties of the carbon fibres were determined.

Fibres were tested at room temperature instead of elevated temperature due to the experimental difficulties of controlling the atmospheric conditions during the heating period and testing. Previous work by Sauder et al. [25] under high temperature and vacuum conditions indicated that the modulus and strength remain constant up to $900^{\circ} \mathrm{C}$, which is above the investigated temperature in this work. The room temperature results are therefore considered representative of results at high temperature.

The tensile modulus and strength of single fibres extracted from the heat-treated bundles were measured using a $2.5 \mathrm{~N}$ Instron 4501 operated at a cross-head displacement rate of $0.1 \mathrm{~mm} / \mathrm{min}$. Each fibre was mounted on a thin cardboard support frame containing a $20 \mathrm{~mm}$ long rectangular cut-out. The cut-out defines the fibre gauge length according to ASTM C1577-03. Prior to testing, the diameter of each individual fibre before heat-treatment (for the control specimens) or after heating was measured and averaged over its gauge length using a LS101 Mitutoyo laser micrometer. The fibres were then tested under monotonically increasing load to failure to determine the elastic modulus and tensile strength. The measured (actual) fibre diameter was taken into account in the calculation of the tensile modulus and strength. A minimum of 30 fibres were tested for each heat-treatment condition.

Weibull parameters for the fibre strength were derived using the two-parameter Weibull strength distribution [26]: 


$$
P_{f}(\sigma)=1-\exp \left(-\left(\frac{\sigma}{\sigma_{0}}\right)^{m}\right)
$$

where $P_{\mathrm{f}}$ is the failure probability, which is a function of the applied stress. The two parameters - $\sigma_{o}$ and $m$ - were calculated according to the maximum likelihood method, and the 95\% confidence intervals for both parameters were determined as outlined in ASTM standard C 1239-00. A twoparameter distribution implies that fibre strength is controlled by a single flaw type, such as a surface crack. This could not be validated based on fracture surface analysis or microstructural examination of the fibres, although the strength results for each heat-treatment condition form a straight line which is indicative of a single flaw type. However, it is noted that the small number of tested fibres for each heat treatment condition (30 samples) does not allow for identification of the statistical failure distribution [27]. As the main aim of this work is a comparison of the average fibre strength as a function of temperature and atmosphere, performing the analysis using the Weibull distribution is deemed adequate.

\section{$3 \quad$ RESULTS \& DISCUSSION}

\subsection{Structural Performance of Carbon Fibre-Epoxy Laminate in Fire}

The tensile performance of the carbon fibre-epoxy laminate while under simulated attack from fire was determined experimentally by performing structural tests at radiant heat flux levels of 35 and 50 $\mathrm{kW} / \mathrm{m}^{2}$. Figure 2 shows the temperature rise at the front and back surfaces of the laminate with increasing exposure time to the heat flux. The front surface, which was exposed directly to the heat flux, heated up rapidly and reached a maximum temperature of $\sim 500^{\circ} \mathrm{C}$ and $600^{\circ} \mathrm{C}$ for the heat fluxes of 35 and $50 \mathrm{~kW} / \mathrm{m}^{2}$, respectively. As expected, the heat-up rate of the back surface was slower due to the low through-thickness thermal conductivity of the carbon-epoxy laminate, and it therefore took longer to reach the equilibrium temperature at the back face for the low and high heat flux levels. The glass transition temperature of the laminate was $128^{\circ} \mathrm{C}$, and thermogravimetric analysis (TGA) revealed that decomposition of the epoxy matrix occurred over the temperature range of $350-480^{\circ} \mathrm{C}$. This indicates that softening followed by decomposition of the matrix phase began at the front surface of the laminate after about 15 and 90 seconds for the heat flux of $35 \mathrm{~kW} / \mathrm{m}^{2}$, respectively, and after only 10 and 55 seconds for $50 \mathrm{~kW} / \mathrm{m}^{2}$ (as indicated in figure 2). Softening and decomposition of the matrix phase extended in the through-thickness direction of the laminate with increasing time and reaches the back surface after 55 seconds and 220 seconds for the heat flux of $35 \mathrm{~kW} / \mathrm{m}^{2}$ and about 50 and 170 seconds for $50 \mathrm{~kW} / \mathrm{m}^{2}$. This reveals that the entire epoxy matrix phase had undergone a brittle-to-rubbery phase transformation and then commenced decomposition into volatile gases and 
char within a relatively short period of time (less than four minutes) at the two heat flux levels. Full decomposition of the matrix system did not occur for the heat flux of $35 \mathrm{~kW} / \mathrm{m}^{2}$ as the back surface only reaches a temperature of around $450^{\circ} \mathrm{C}$. However, at this temperature the matrix was severely decomposed and had little residual stiffness and strength.

Figure 3 shows the effect of applied tensile stress on the failure time of the carbon-epoxy laminate when exposed to the heat flux of 35 or $50 \mathrm{~kW} / \mathrm{m}^{2}$. The applied stress is expressed as absolute stress and the percentage of the tensile failure stress of the laminate at $20^{\circ} \mathrm{C}$. The failure time increased rapidly when the applied stress was reduced down to a threshold level, below which failure did not occur. The threshold stress level was about $50 \%$ and $35 \%$ of the ultimate strength for the heat fluxes of 35 and $50 \mathrm{~kW} / \mathrm{m}^{2}$, respectively. Similar trends between applied tensile stress and failure time have been measured for fibreglass laminates [11].

Based on the temperature measurements, the entire matrix phase in the through-thickness direction of the laminate exceeded the glass transition temperature within 55 and 50 seconds for the low and high heat flux. Figure 3 shows that the laminate (with a fully softened matrix) was still able to carry the applied tensile stress beyond these times. Even following full decomposition of the matrix phase (which takes less than four minutes), the laminate did not fail when the applied stress was below the threshold limit. This reveals that the carbon fibres carried the applied stress after the matrix had thermally softened and decomposed to char, although fibre weakening must have occured because the laminate eventually failed due to fibre rupture when the applied stress was above the threshold limit. Therefore, understanding the tensile weakening of carbon fibres at high temperatures is important in determining the tensile structural integrity and survivability of carbon fibre composites in fire.

\subsection{Mass Loss and Oxidation Kinetics of Carbon Fibre}

The mass loss of carbon fibre when heated in air or nitrogen was determined using TGA, and the results are presented in figure 4. Heating in both nitrogen and air caused a very small loss in mass $(0.8 \%)$ over the temperature range of $300-500^{\circ} \mathrm{C}$ due to decomposition of the organic-based sizing compound on the carbon fibre (as seen in the figure insert). This amount of mass loss and the decomposition temperature is typical for the types of sizing compounds used on carbon fibres [1]. The carbon fibre experienced a large mass loss when heated in air between about $500-950^{\circ} \mathrm{C}$ due to oxidation. The least-squares fitting procedure for a single-stage Arrhenius-dependent oxidation process for three different heating rates resulted in an activation energy of $Q_{\mathrm{ox}}=148 \mathrm{~kJ} / \mathrm{mol}$, a rate constant of $A=16700 \mathrm{~s}^{-1}$ and an order of reaction of $n=0.59$ for the T700 fibres. The solid line through the TGA data for a heating rate of $20^{\circ} \mathrm{C} / \mathrm{min}$ in figure 4 is the obtained curve fit as given by the Arrhenius parameters. 
The mass loss of the carbon fibres in air was also determined under iso-thermal conditions, and the results are presented in figure 5. Measurable mass loss did not occur until the temperature exceeded $500-550^{\circ} \mathrm{C}$, and as expected the mass loss rate increased with temperature. Prolonged heating in air eventually resulted in complete oxidation of the carbon fibre, which was signified by no residual mass.

A strong correlation was found between the mass loss and the diameter of carbon fibre when heated in air. Figure 6 shows the relationship between mass loss and fibre diameter based on over 500 measurements at different temperatures and exposure times between 500 and $700^{\circ} \mathrm{C}$. It was not possible to test fibres with a diameter less than $3 \mu \mathrm{m}$, and therefore the experimental results are confined to mass losses up to $65 \%$. The curve in figure 6 shows the calculated reduction in fibre diameter when it was assumed that mass loss is linearly related to the reduction in load-bearing area of the fibre due to surface oxidation. The fibre density was assumed constant irrespective of possible variations in the microstructure from the outer fibre surface to the fibre core. The correlation between mass loss and diameter loss is evidence that uniform thinning of the carbon fibres occurred due to surface oxidation. The uniform diameter reduction was confirmed from an examination of fibres using SEM following heat-treatment in air (figure 7). The fibre diameter does not change when heating occurred in nitrogen except for a very small thinning above $350-400^{\circ} \mathrm{C}$ due to removal of the sizing compound.

Based on the experimental testing and analysis, it appears that the carbon fibres in air lose significant mass between $500-950^{\circ} \mathrm{C}$ due to surface oxidation which resulted in uniform thinning. The oxidation process does not appear to cause significant surface damage. The surface of the original fibre (before heat treatment) was smooth, while after heating above $350-400^{\circ} \mathrm{C}$ it was covered with very shallow grooves aligned along the fibre axis, as shown in figures 7(a) and 7(b) respectively. The grooves were not caused by heating because they were also present on the original fibre; however they were masked by the size coating. The surfaces of all the fibres contained shallow grooves which do not appear to change size, shape or depth following heating at different temperatures. The fibres did not loss mass (and subsequently retained their original size) when heated in nitrogen, except for the small loss due to thermal decomposition of the size.

Based on these findings, it is expected that carbon fibres in a hot, decomposing composite exposed to fire will experience different physical responses. The fibres at the heated composite surface decompose and become thinner when the temperature exceeds $500^{\circ} \mathrm{C}$ because they are in direct contact with air. The oxidation process occurred at a constant rate across the fibre surface, and there were no obvious signs of oxidation-induced damage (e.g. cracks, pits). Below the composite surface the fibres are expected to remain unchanged (expect for decomposition of the size coating) because 
out-gassing of volatile gases (e.g. low molecular hydrocarbons) from the decomposing epoxy matrix will impede the ingress of air and thereby suppresses fibre oxidation.

\subsection{Elastic Properties of Carbon Fibres in an Oxidising or Inert Atmosphere}

The effect of temperature on the Young's modulus of carbon fibre following heat-treatment in air or nitrogen is shown in figure 8 . The diameter of the fibres was used to calculate the tensile modulus. The elastic modulus remained unchanged when heated in nitrogen (original modulus $E=226 \pm 9.5 \mathrm{GPa}$ ), which is the same result as reported by Sauder et al [25] for fibres heated in vacuum. However, the modulus decreased in air when fibres were heated above $\sim 550^{\circ} \mathrm{C}$. Because the fibre modulus does not change when heating occurred in nitrogen, the results suggest that the temperature alone is not responsible for the loss in stiffness which occurred occurs in air. The reduction in fibre modulus in air must be associated with the mass loss caused by surface oxidation.

Figure 9 shows the relationship between mass loss and Young's modulus for the carbon fibre when heated in air. The standard deviation for the experimental values increases with the percentage mass loss, and this is attributed to increased variability in the amount of oxidation-induced thinning along the length of the tested fibre. Despite the scatter, the experimental data shows a two-stage trend where the fibre modulus initially decreased with increasing mass loss until a steady-state elastic modulus value $\left(E_{\text {core }}=175 \mathrm{GPa}\right)$ was reached when the mass loss exceeded $35 \%$. This trend is attributed to a skin-core heterogeneity of the microstructure for T700 carbon fibre; consisting of a high stiffness surface region and a lower modulus core. Several early studies of PAN-based carbon fibres report that the outer fibre surface region consists of layer planes which have a higher degree of orientation with the fibre axis than the turbostratic carbon layers within the fibre core [28-34]. It is believed that the basis for the micro-structural inhomogeneity in carbon fibres originates during the oxidation of the PAN precursor (stabilisation phase) [30, 31] or during the heat-treatment phase at high temperature due to restrained surface layer ordering [32]. Figure 9 includes an idealised illustration of the twolayer structure, with the thickness of the highly-aligned outer layer being denoted by $t_{\text {outer }}\left(2 t_{\text {outer }}=d_{0}\right.$ $\left.d_{\mathrm{i}}\right)$. Note that this illustration is a simplified representation, and the boundary between the outer layer and core is most likely not abrupt (i.e. within the distance of a single basal plane) but instead occurs over a narrow distance. Using x-ray diffraction, Wicks and Coyle [30] measured the outer layer thickness to a high strength carbon fibre to be about $1 \mu \mathrm{m}$, although the thickness depends on the processing conditions (particularly the carbonizing temperature) used in fibre manufacture.

Skin-core heterogeneity can result in a non-uniform stiffness distribution through the fibre crosssection $[29,33,34]$. The data presented in figure 9 can be used to calculate the thickness and modulus of the surface region of highly-aligned layers using rule-of-mixtures analysis. When it is assumed that 
the skin-core structure can be idealised as a two-layer cylinder, then the average fibre modulus is related to the moduli of the skin and core via rule-of-mixtures of their load-bearing areas:

$$
E_{a v}=\frac{A_{i}}{A_{o}} E_{\text {core }}+\frac{\left(A_{\text {total }}-A_{i}\right)}{A_{\text {total }}} E_{\text {surface }} \text { with } A_{i}=\frac{\pi r_{i}^{2}}{4} \text { and } A_{\text {total }}=\frac{\pi r^{2}}{4}
$$

where $A_{o}\left(r_{o}\right)$ and $A_{i}\left(r_{i}\right)$ are the load-bearing area (radius) of the original and heat-treated fibre, and $E_{\text {core }}$ and $E_{\text {surface }}$ are the Young's moduli of the core and surface regions of the fibre. A steady-state value for the modulus was obtained with 35\% mass loss or - when expressed in terms of load-bearing area - a reduced average radius $\left(r_{i}\right)$ of $2.7 \mu \mathrm{m}$. This resulted in a value for the outer layer thickness ( $\left.t_{\text {outer }}\right)$ of $0.65 \mu \mathrm{m}$, which is about $20 \%$ of the original fibre diameter $\left(d_{0}=6.7 \pm 0.3 \mu \mathrm{m}\right)$. The application of the rule-of-mixtures analysis to calculate the surface layer thickness was based on the assumption that the modulus properties of the surface layer and core did not change during heat treatment. This assumption was supported by the fact that the heat-treatment temperatures used in this study were low compared to the final heat-treatment temperatures used in the manufacture of T700 carbon fibres $\left(\sim 1500^{\circ} \mathrm{C}\right)$, and therefore below the temperature at which a structural change of PANbased carbon fibres is encountered [25, 35].

The Young's modulus of the outer layer can be calculated using the two-layer model:

$$
E_{\text {surface }}=\frac{r_{o}^{2}}{\left(r_{o}^{2}-r_{i}^{2}\right)}\left(E_{a v}-\frac{r_{i}^{2}}{r_{o}^{2}} E_{\text {core }}\right)=315 \mathrm{GPa}
$$

where the modulus of the fibre core $\left(E_{\text {core }}\right)$ is $175 \mathrm{GPa}$, and the average fibre modulus for the asreceived carbon fibre at room temperature $\left(E_{a v}\right)$ is $225 \mathrm{GPa}$. Based on this simple analysis, the outer layer with the highly-oriented layer planes had a much higher Young's modulus ( 40\%) than the fibre core.

The theoretical prediction of modulus loss with increasing mass loss of the carbon fibre (based on Eq. (2)) is plotted in figure 9. The agreement with the experimental modulus data was good, and shows the two-layer model was capable of explaining the measured loss in fibre stiffness due to heat-treatment in air.

\subsection{Strength Properties of Carbon Fibres in an Oxidising or Inert Atmosphere}


Figure 10 presents examples of the Weibull strength distribution for carbon fibre before and after heating in air or nitrogen. The measured diameter of the fibre was used to calculate the tensile strength from the failure load. The example plots are shown for the fibre in the original condition and after heat treatments of $500^{\circ} \mathrm{C}$ for 30 minutes (which results in partial strength loss) or $650^{\circ} \mathrm{C}$ for 1 hour (full strength loss) for both atmospheric conditions. The strength plots in all cases show a linear relationship which is indicative of a two-parameter Weibull distribution, and this implies the that fibre strength was controlled by a single defect type. The Weibull parameter $m$ describes the variation of fibre strength for a given defect population. The Weibull parameter $(m)$ was similar in all cases, which indicates that the variability in the critical defect size does not change significantly due to heat treatment. While it was found that the fibre modulus was dependent on the atmosphere, the reduction in fibre strength was identical whether heating occurs in air or nitrogen, provided the reduced diameter of the fibres for air treatments was taken into account. Therefore, the strength loss was dependent on the temperature, but was not related to fibre thinning nor oxidation which occurred in air.

The effect of temperature on fibre strength in air is shown in figure 11 for the two selected heattreatment times of 30 mins and 2 hours. The nitrogen results were identical (within one standard deviation) and therefore are not included. The fibre strength decreased over the temperature range of $400-600^{\circ} \mathrm{C}$, and at higher temperatures (up to $700^{\circ} \mathrm{C}$ ) or longer exposure times (up to four hours, not shown in figure 11) the average strength remained at the reduced steady-state value of $\sim 3150 \mathrm{MPa}$ (or $45 \%$ of the original strength).

For the development of strength-based models, the fibre strength loss may be described as a function of temperature alone, as the time effect is less significant. The previously developed mathematical function for composite strength loss $[10,11]$ allows for convenient data fitting:

$$
\sigma(T)=\frac{\sigma_{0}+\sigma_{R}}{2}-\frac{\sigma_{0}-\sigma_{R}}{2} \tanh \left(k_{f}\left(T-T_{50 \%}\right)\right)
$$

where $\sigma_{0}$ is the room-temperature fibre strength (5400 MPa) and $\sigma_{\mathrm{R}}$ is the steady-state reduced fibre strength of $3150 \mathrm{MPa}$. The parameter $k_{\mathrm{f}}$ describes the rate of strength loss and is fitted as $k_{\mathrm{f}}=0.021$. $T_{50 \%}$ denotes the temperature, at which $50 \%$ of the fibre strength is lost $\left(T_{50 \%}=492^{\circ} \mathrm{C}\right)$.

The strength loss of the carbon fibre laminate exposed to fire exceeded the determined carbon fibre strength loss. Figure 3 showed that the carbon-epoxy laminate exposed to the heat flux of $35 \mathrm{~kW} / \mathrm{m}^{2}$ (maximum temperature of $\sim 500^{\circ} \mathrm{C}$ ) failed in tension when the applied stress was above $50 \%$, and failure did not occur below this value. Similarly, the laminate did not fail when exposed to $50 \mathrm{~kW} / \mathrm{m}^{2}$ $\left(T_{\max }=600^{\circ} \mathrm{C}\right.$ ) when the applied tensile stress was under about $35 \%$. On the other hand, the fibre 
strength measurements in figure 11 show a retained strength of about $70 \%$ and $45 \%$ when heated to $500^{\circ} \mathrm{C}$ and $600^{\circ} \mathrm{C}$, respectively. Previous work by the authors showed that shear lag effects due to matrix softening played a significant role for predictive models for glass-fibre composites under tension and one-sided heating [11]. The additional loss of fibre diameter at the oxidising surface layer will also need to be considered and results in strength reduction due to reduction of the load-bearing fibre area. Both mechanisms resulted in a higher laminate strength reduction when compared to the single fibre results.

Heat treatment led to removal of sizing independent of atmosphere, as shown in Figure 4. Surface damage to the fibres following heat-treatment and sizing removal may cause the loss in strength, although obvious signs were not observed using SEM (see also Figure 7). As mentioned, the strength distribution for the carbon fibres showed a two-parameter Weibull distribution (as shown in figure 10) which suggests their strength was controlled by a single type of flaw (e.g. crack, pit). While the flaw type was not identified using SEM, its critical size $(c)$ can be calculated from the measured fibre strength $\left(\sigma_{0}\right)$ using linear-elastic fracture mechanics when it is assumed the flaw occurs at the surface:

$c=\frac{\pi}{4}\left(\frac{K_{I c}}{\sigma_{0}}\right)^{2}$

$K_{I c}$ is the mode I fracture toughness, which for PAN-based carbon fibre is about 1.0 MPa.m ${ }^{0.5}$ [36]. $Y(c, R)$ is a geometric stress concentration factor dependent on the ratio of fibre radius $(R)$ and flaw size. $Y(c, R)$ equals $2 / \pi$ for a semicircular surface flaw, provided the flaw is much smaller than the fibre radius. If the fibre toughness is assumed to be unchanged by heat-treatment, the critical flaw size in the carbon fibres was calculated to increase slightly - from $25 \mathrm{~nm}$ for the original fibre to $85 \mathrm{~nm}$ for the heat-treated fibres with steady-state strength loss - as shown in figure 12. Within this nanometer range the concept of a sharp crack does most likely not hold, and therefore the calculations should not be considered quantitatively accurate. However, the analysis does indicate that a very small increase in the critical flaw size due to high temperature exposure can account for the large reductions in fibre strength which occur when the carbon fibre-polymer composites were exposed to fire.

\section{CONCLUSIONS}

Final failure of carbon fibre-polymer composites under combined tensile loading and exposure to fire is determined by the retained strength of the fibre reinforcement. Carbon fibre composites can continue to support an applied load (albeit with some loss in strength) after the polymer matrix phase has thermally softened and decomposed due to the retained strength of the load-bearing fibres. The 
experimental research presented in this study revealed that carbon fibres at the heated surface of a composite material will thermally decompose and become thinner due to oxidation when the temperature exceeds $\sim 500-550^{\circ} \mathrm{C}$. The decomposition rate increased rapidly, with a corresponding rapid loss in fibre thickness, with increasing temperature above $550^{\circ} \mathrm{C}$. Surface decomposition by oxidation removes the modulus contribution of the highly-oriented layer planes, which resulted in fibre softening. The fibre strength was also reduced due to thermally-activated damage, presumably the development of sub-micron flaws at the surface. The reduction in fibre strength was dependent on the temperature, and provided the applied tensile stress acting on a hot, decomposing composite material does not exceed the fibre strength then failure did not occur.

The response of carbon fibres below the composite surface to fire is different to the surface fibres. Air cannot diffuse into the composite because of the out-gassing of volatiles generated by decomposition of the polymer matrix. Provided oxygen is absent, the sub-surface fibres do not thermally decompose and lose stiffness due to fire. However, the strength of the fibres do decrease by the same amount as for the surface fibres, and again provided the fibre strength is not exceeded then the composite does not fail in tension.

\section{Acknowledgements}

The research work was supported by the United States Office of Naval Research (Grant No N0001408-11253) under the direction of Dr Luise Couchman. The research was performed as part of project P2.1.2 of the Cooperative Research Centre for Advanced Composite Structures. The authors thank Robert Ryan (RMIT University) for technical assistance with the composite fabrication, Naadia Nawaz (RMIT University) for structural testing, Gary Mathys (Defence Science and Technology Organisation) for TGA, and Richard Muscat (Defence Science and Technology Organisation) for SEM analysis.

\section{References}

1. Mouritz AP, Gibson AG. Fire Properties of Polymer Composite Materials, Dordrecht, Springer, 2006.

2. Mouritz AP, Feih S, Kandare E, Mathys Z, Gibson AG, Des Jardin PE, Case SW, Lattimer BY. Review of fire structural modelling of polymer composites, Comp., (2009);40A:1800-1814.

3. Asaro RJ, Lattimer B, Ramroth W. Structural response of FRP composites during fire, Comp Struct, (2009);87:82-393.

4. Gu P, Asaro RJ. Designing sandwich polymer matrix composite panels for structural integrity in fire, Comp Struct, (2009);88:461-467.

5. Lua J., O'Brien J, Key CT, Wu Y, Lattimer BY. A temperature and mass dependent thermal model for fire response prediction of marine composites, Comp. 2006;37A:1024-1039.

6. Boyd SE, Case SW, Lesko JJ. Compression creep rupture behavior of a glass/vinyl ester composite subject to isothermal and one-sided heat flux conditions. Comp. 2007;38:1462-1472.

7. Gibson AG, Wright PNH, Wu YS, Mouritz AP, Mathys Z, Gardiner CP. The integrity of polymer composites during and after fire. JCompMat 2004;38:1283-1308. 
8. Gibson AG, Wu YS, Evans JT, Mouritz AP, Laminate theory analysis of composites under load in fire. JCompMat 2006;40:639-658.

9. Feih S, Mathys Z, Gibson AG, Mouritz AP. Modelling the compression strength of polymer laminates in fire Comp. 2007:38A:2354-2365.

10. Feih S, Mathys Z, Gibson AG, Mouritz AP. Modelling the tension and compression strengths of polymer laminates in fire, Comp.Sci.Tech. 2007;67:551-564.

11. Feih S, Mouritz AP, Mathys Z, Gibson AG, Tensile strength modelling of glass fiber-polymer composites in fire , JCompMat 2007;41:2387-2410.

12. Easby RC, Feih S, Konstantis C, La-Delfa G, Urso Miano V, Elmughrabi A, Mouritz AP, Gibson AG. A failure model for phenolic and polyester pultrusions under load in fire. Plas.Rubb.Comp., 2007;36:379388.

13. Griffis CA, Nemes JA, Stonesifer FR, Chang CI. Degradation in strength of laminated composites subjected to intense heating and mechanical loading. JCompMat 1986;20:216-235.

14. Pering GA, Farrell PV, Springer GS. Degradation of tensile and shear properties of composites exposed to fire or high temperature. JCompMat 1989;14:54-66.

15. McManus HL, Springer GS. High temperature behaviour of thermomechanical behaviour of carbonphenolic and carbon-carbon composites, II. Results. JCompMat 1992;26:230-255.

16. Mouritz AP. Fire resistance of aircraft composite laminates, JMatSciLett. 2003;22:1507-1509.

17. Seggewiss PGB. Methods to evaluate the fire resistance of carbon fiber reinforced plastics, In: Proceedings of the 60th SAMPE Symposium \& Technical Exhibition, Long Beach, CA, 2004.

18. Burns LA, Feih S, Mouritz AP. Composite properties of carbon-epoxy laminate in fire, JAircraft, 2010:27:528-533.

19. Nawaz N, Feih S, Mouritz AP. Compressive failure of aerospace carbon fibre/nomex honeycomb core sandwich composites in fire, Comp. A, (submitted).

20. Berlin P, Dickman O and Larsson F. Effects of heat radiation on carbon/PEEK, carbon/epoxy and glass/epoxy composites, Composites 1992; 23: 235-243.

21. Nakada M, Miyano Y, Kinoshita M, Koga R, Okuya T and Muki R. Time-temperature dependence of tensile strength of unidirectional CFRP, J Comp Mater 2002; 36: 2567-2581.

22. Cao S, Wu Z and Wang X. Tensile properties of CFRP and Hybrid FRP composites at elevated temperature, J Comp Mater 2009; 43: 315-330.

23. Lamouroux F, Bourrat X, Nasalain R, Sevely J. Structure/oxidation behaviour relationship in the carbonaceous constituents of 2D-C/PyC/SiC composites, Carbon 1993;31:1273-1288.

24. Yin Y, Binner GP, Cross TE, Marshall SJ. The oxidation behaviour of carbon fibres, JMatSci 1994;29:2250-2254.

25. Sauder C, Lamon J and Pailler R. The tensile behaviour of carbon fibers at high temperatures up to 2400 C, Carbon 2004; 42: 715-725.

26. Khalili A and Kromp K. Statistical properties of Weibull estimators. JMatSci 1991;26:6741-6752.

27. Danzer R. Some notes on the correlation between fracture and defect statistics: Are Weibull statistics valid for very small specimens? J.Eur Cer Society 2006;26:3043-3049.

28. Jones BF, Duncan RG. The effect of fibre diameter on the mechanical properties of graphite fibres manufactured from polyacrylonitrile and rayon. JMatSci., 1971;6:289-293.

29. Diefendorf RJ, Tokarsky E. High-performance carbon fibres. Poly Eng \& Sci 1975;15:150-159.

30. Wicks BJ, Coyle RA. Microstructural inhomogeneity in carbon fibres. JMatSci, 1976;11:376-383. .

31. Watt W. Carbon fibres from polyacrylonitrile. In: Strong fibres, editors: Watt W and Perov BV, Handbook of Composites Part A, 327-387.

32. Bennett SC and Johnson DJ. Electron-microscope studies of structural heterogeneity in PAN-based carbon fibres. Carbon 1979; 17: 25-39.

33. Morita K, Murata Y, Ishitani A, Murayama K, Ono T, Nakajima A. Characterisation of commercially available PAN (polyacrylonitrile)-based carbon fibres, Pure \& App. Chem. 1986;58:455-468.

34. Yamanaka K, Nakano S. Quantitative elasticity evaluation by contact resonance in an atomic force microscope, App. Phys, 1998;66A:S313-S317.

35. Guigon M, Oberlin A. Heat-treatment of high tensile strength PAN-based carbon fibres: Microtexture, Structure and Mechanical Properties, CompSciTech 1986;27:1-23.

36. Honjo K. Fracture toughness of PAN-based carbon fibres estimated from strength-mirror size relation, Carbon 2003;41:979. 
Figure 1: Schematic representation of the oxygen levels through a hot, decomposing laminate exposed to fire.

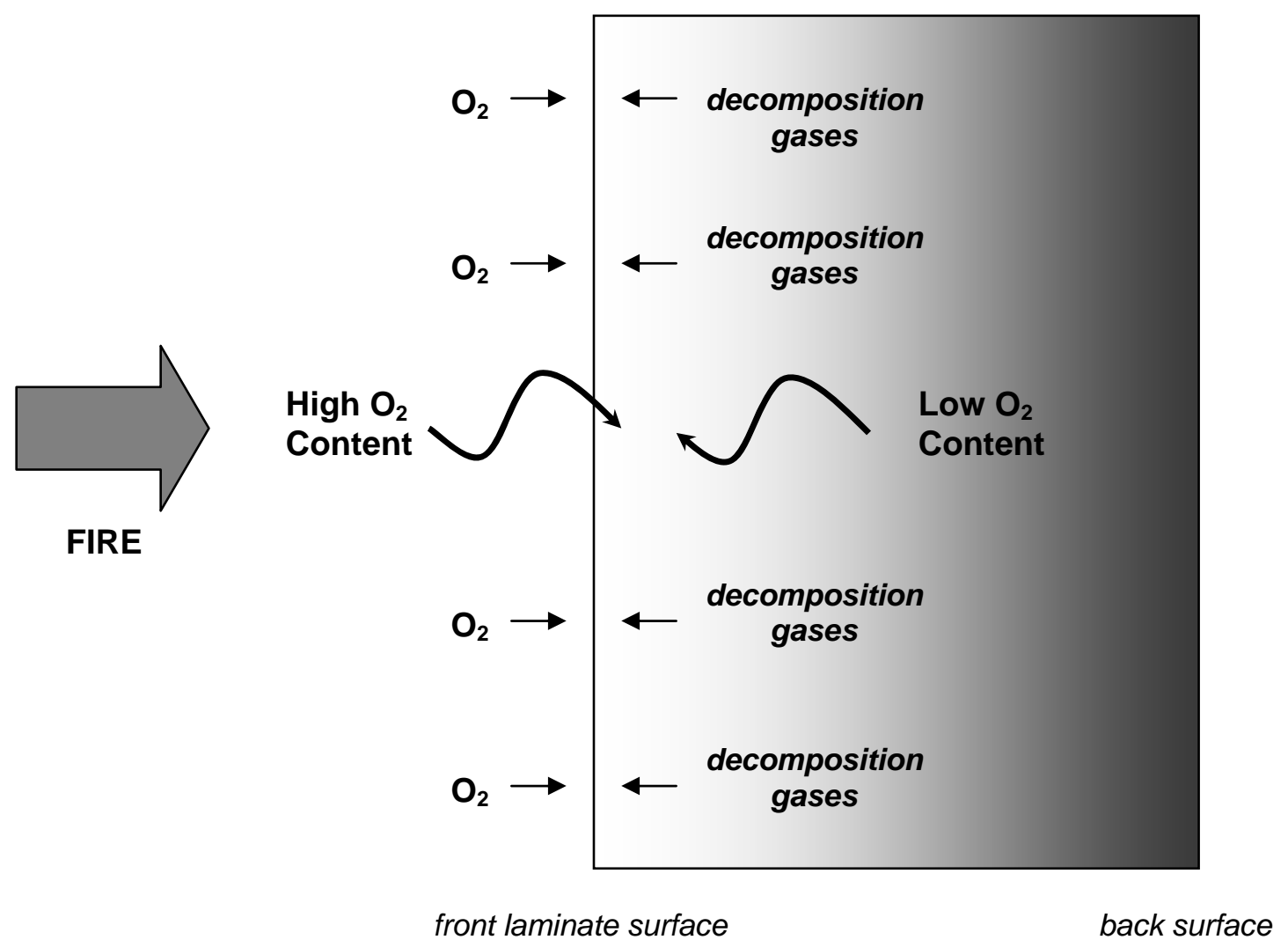


Figure 2: Temperature-time curves measured at the front and back surfaces of the carbon-epoxy laminate when exposed to the heat flux of (a) 35 or (b) $50 \mathrm{~kW} / \mathrm{m}^{2}$. The times at which the front and back surfaces reach the glass transition temperature $\left(T_{\mathrm{g}}\right)$ and decomposition temperature $\left(T_{\text {decomp }}\right)$ of the epoxy matrix are indicated.

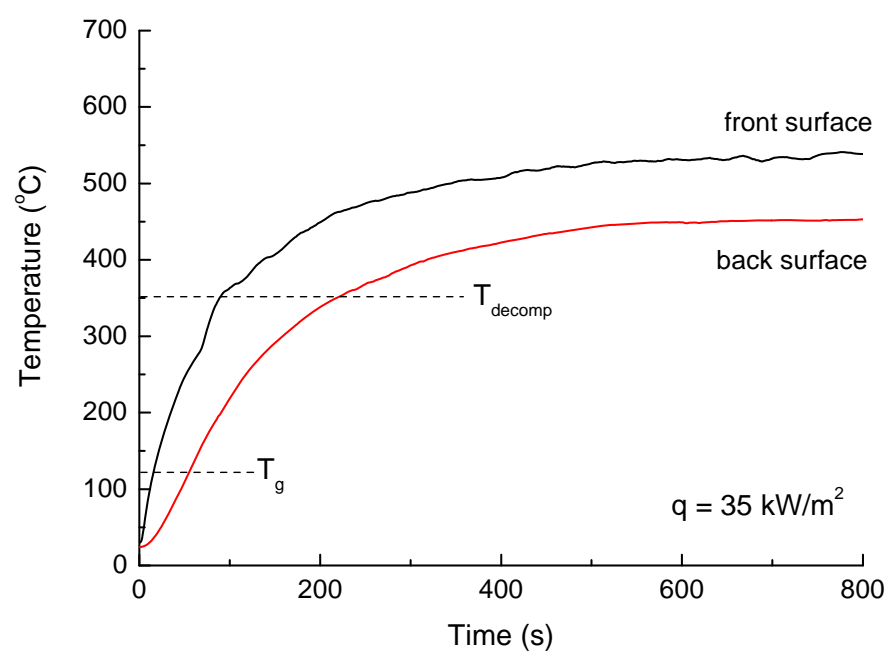

(a)

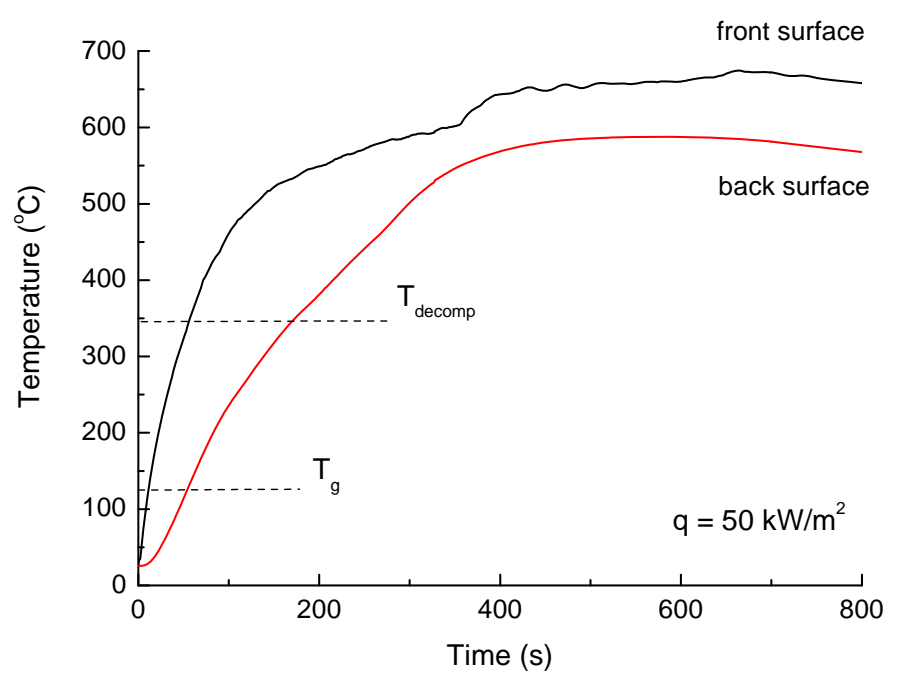

(b) 
Figure 3: Failure time curves for the carbon-epoxy laminate subjected to combined tensile loading and one-sided heating at a heat flux of 35 or $50 \mathrm{~kW} / \mathrm{m}^{2}$. The curves indicate that when the applied tensile stress is above the line then the laminate will fail while below the line the material will not fail. The horizontal arrows indicate specimens that did not fail during the fire structural test.

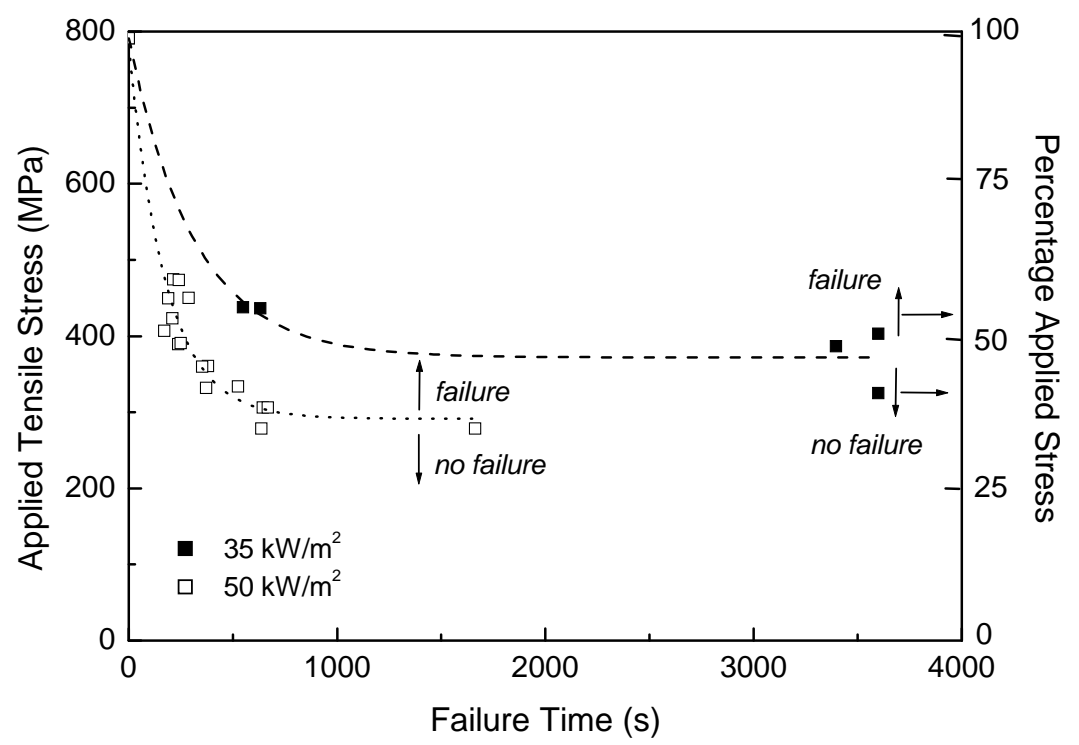


Figure 4: Mass loss-temperature curves for the carbon fibre heated in air or nitrogen determined using TGA at the heating rate of $20^{\circ} \mathrm{C} / \mathrm{min}$. The Arrhenius oxidation parameters determined from TGA for three different heating rates in air are given.

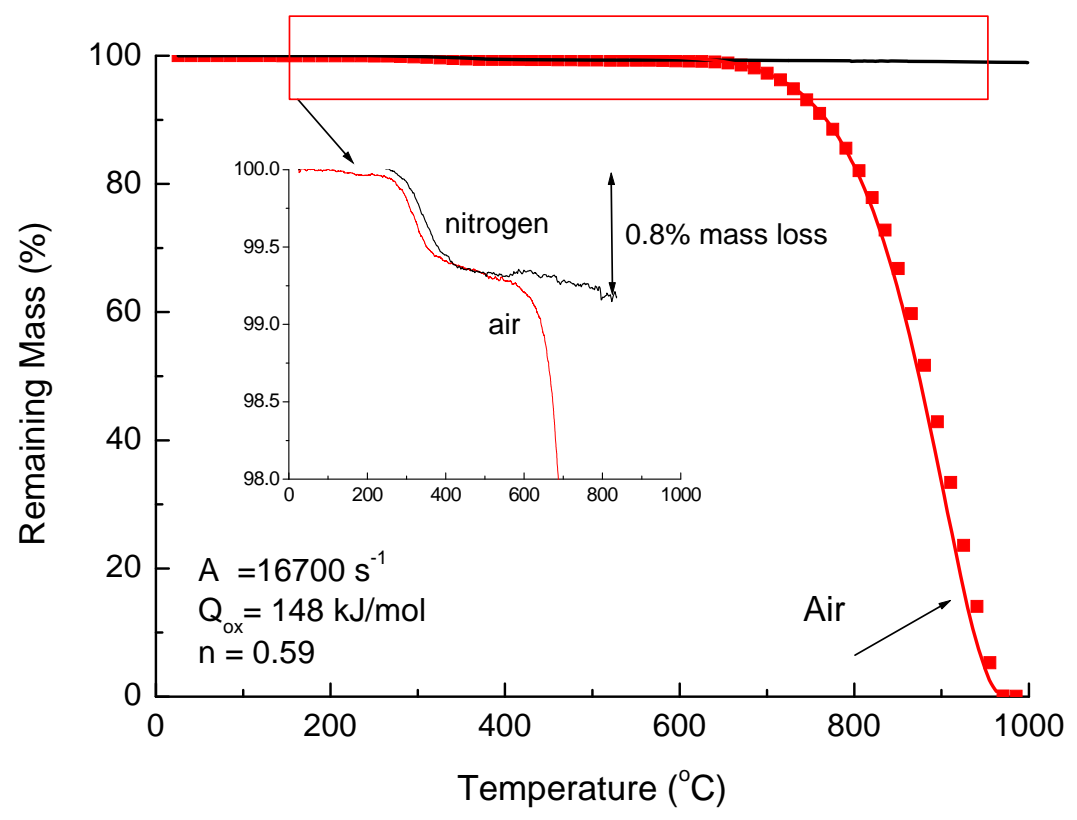


Figure 5: Effect of temperature and heating time on the mass loss of carbon fibre in air.

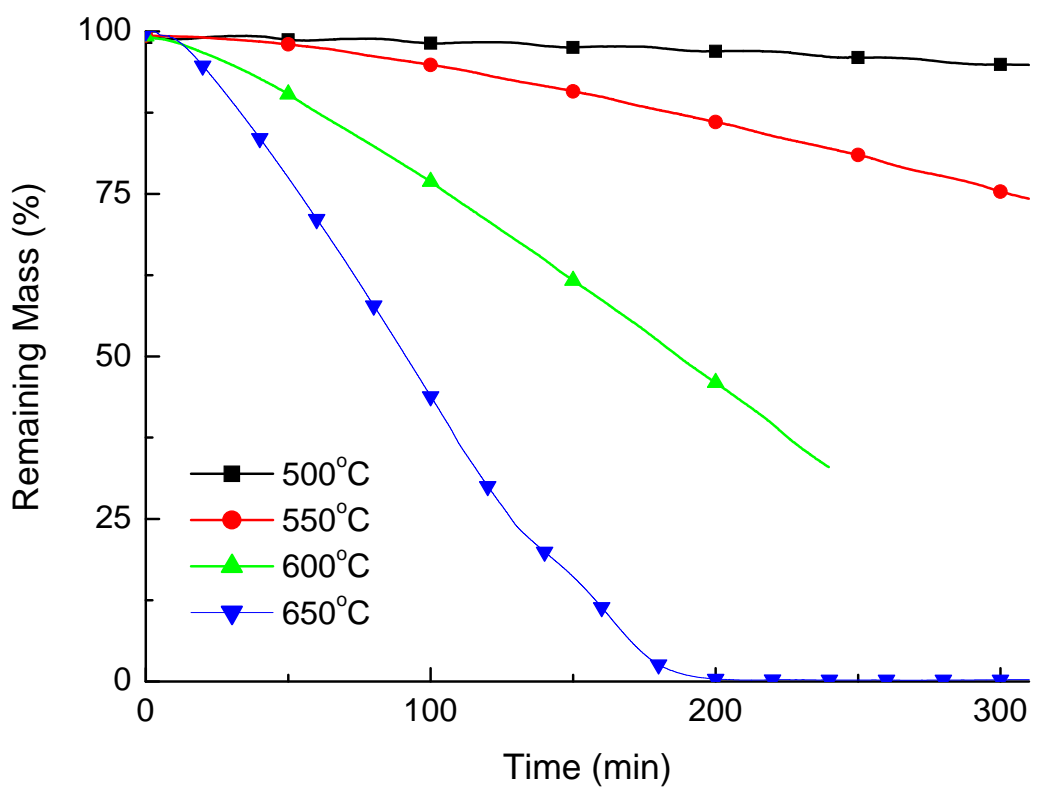


Figure 6: Relationship between mass loss and diameter of the carbon fibre when heated in air. Colours indicate the different temperatures during oxidation.

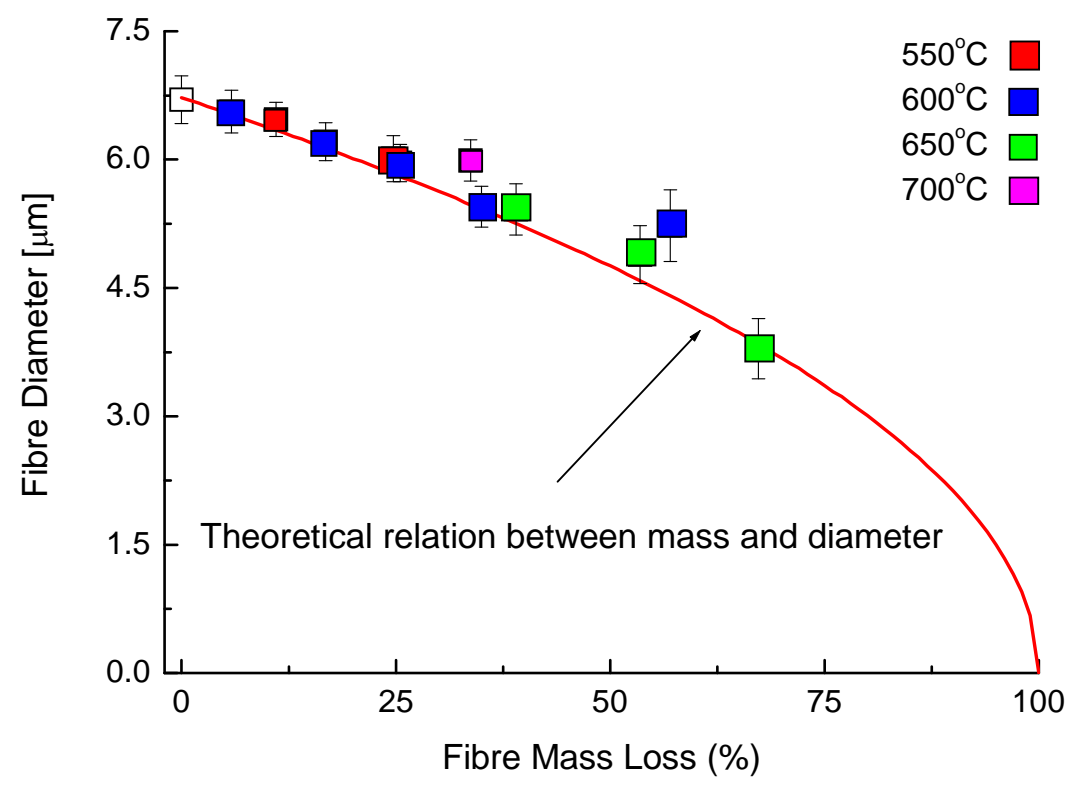


Figure 7: Surface of (a) carbon fibre with sizing $(\mathrm{d}=7 \mu \mathrm{m})$ and (b) carbon fibre heated at $600^{\circ} \mathrm{C}$ for one hour in air $(\mathrm{d}=5.65 \mu \mathrm{m})$

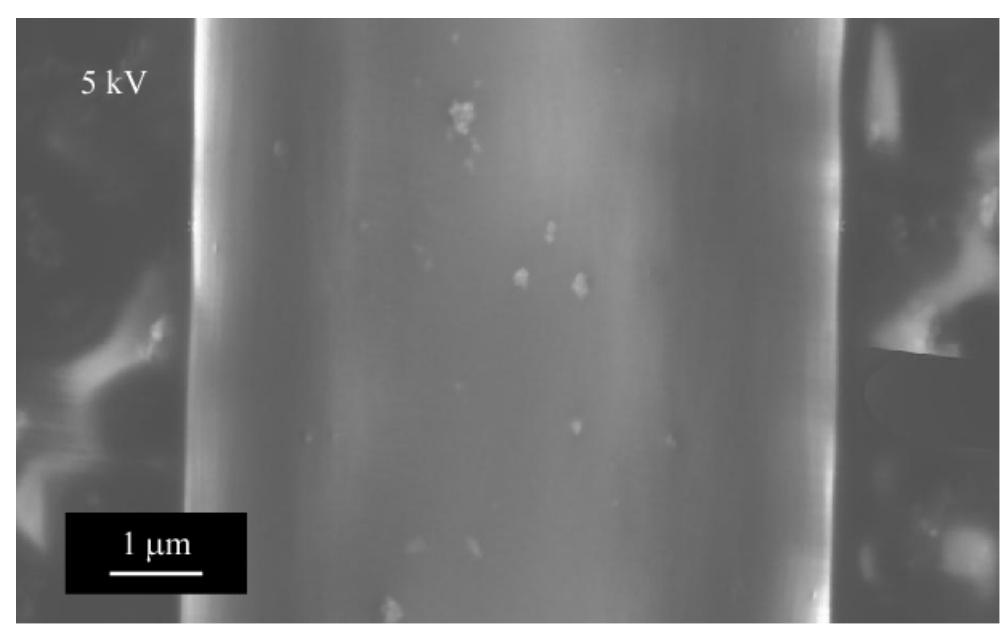

(a)

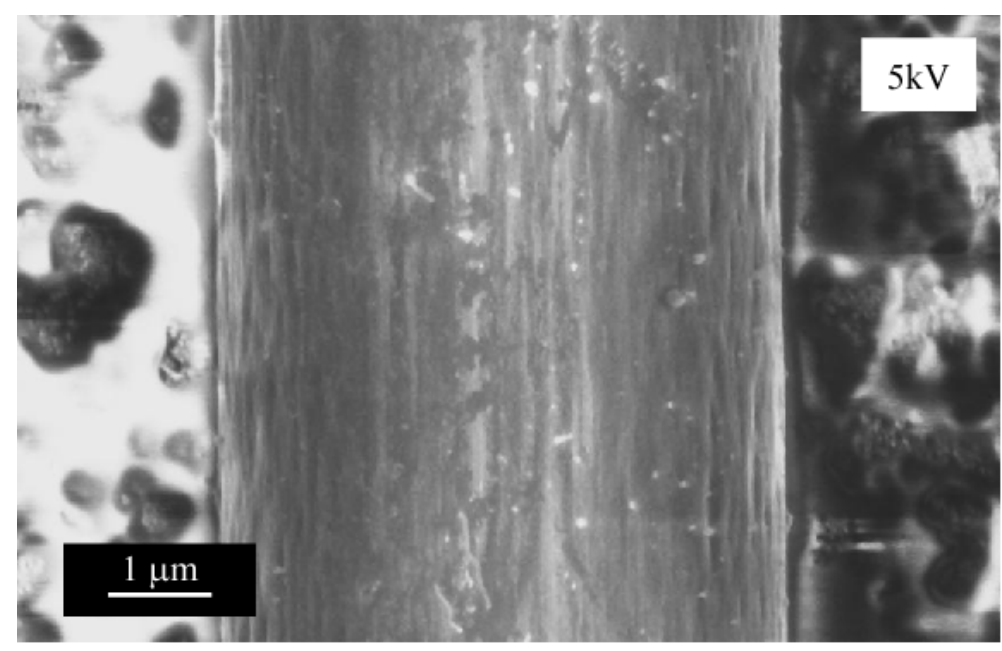

(b) 
Figure 8: Differences in fibre modulus following heat treatment in air or nitrogen for the same heat treatment conditions.

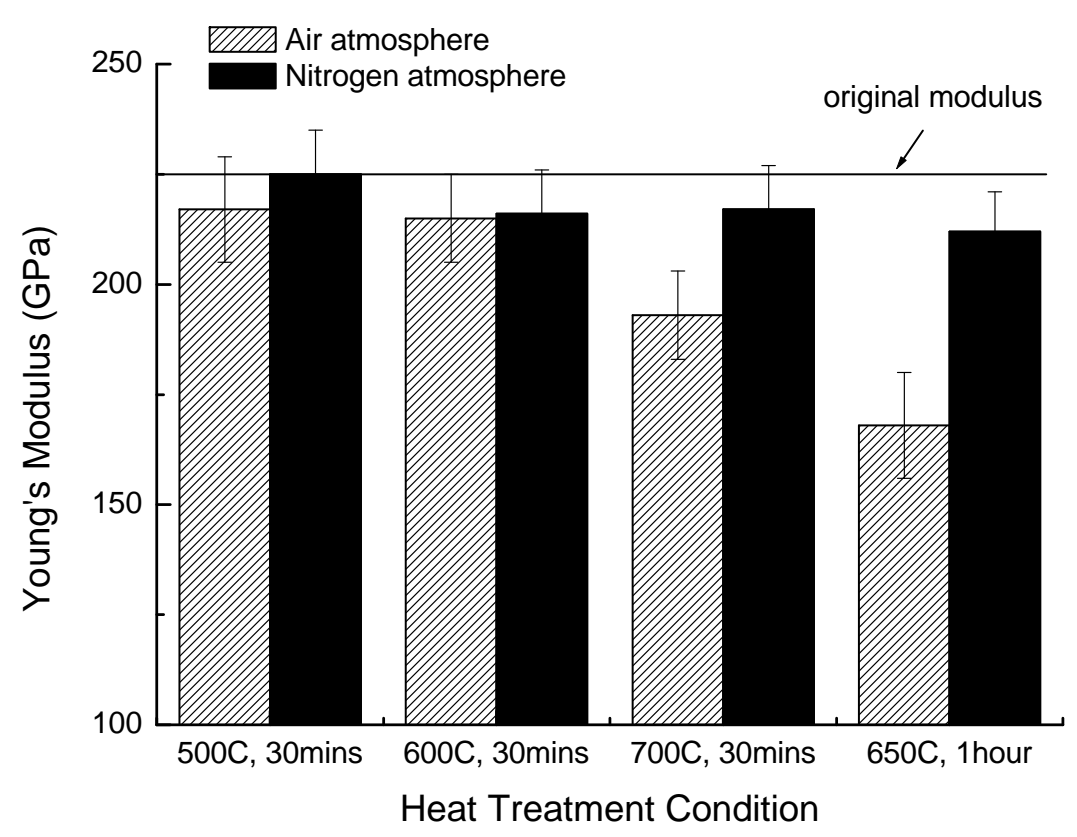


Figure 9: Relationship between Young's modulus and mass loss of carbon fibre when heated in air.

The curve shows the calculated relationship using Eqn. (2). The inset diagram illustrates the two-layer structure of carbon fibre where the modulus values for the outer and inner regions are given.

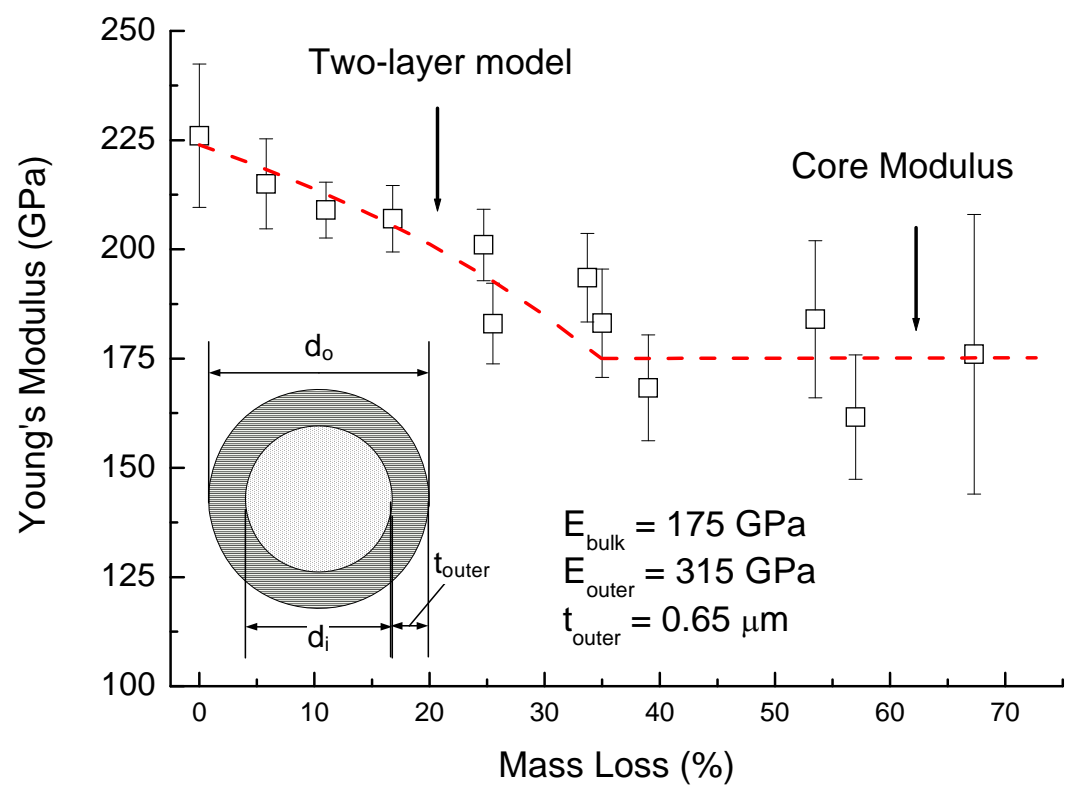


Figure 10: Weibull strength distribution plots for the original carbon fibre and the fibre following heattreatment at (a) $500^{\circ} \mathrm{C}$ and 30 mins (partial strength loss) and (b) $650^{\circ} \mathrm{C}$ for 1 hour (steady-state strength loss). Strength calculation takes the reduced diameter into account for heat treatments in air.

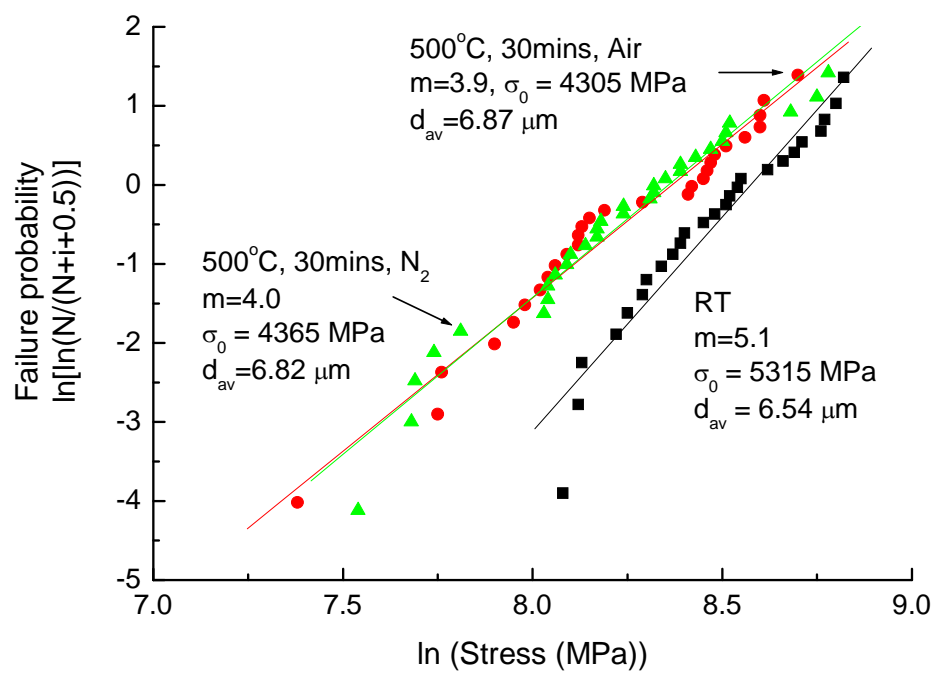

(a)

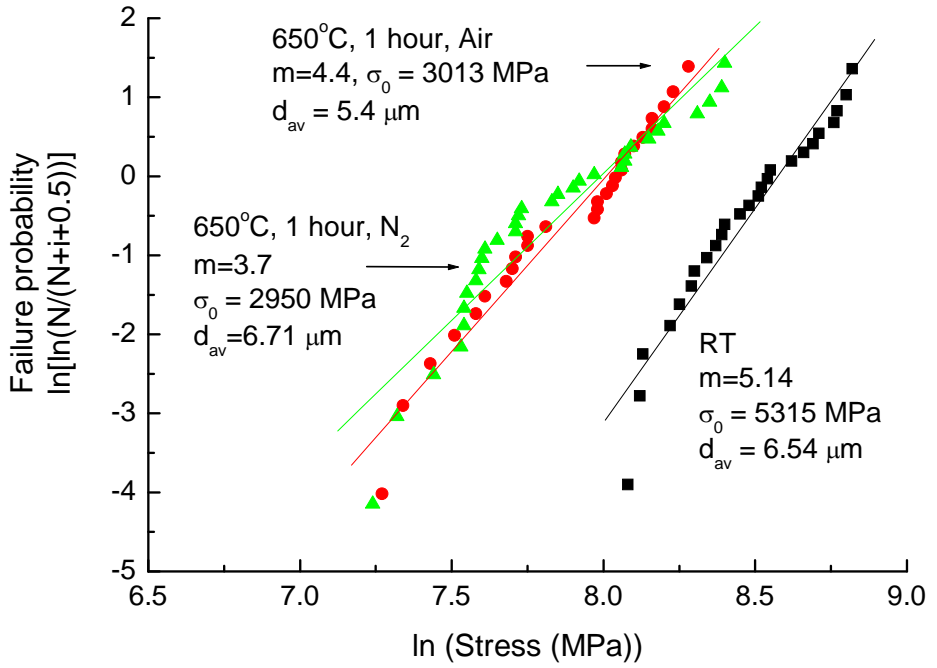

(b) 
Figure 11: Effect of temperature on carbon fibre strength when heated in air.

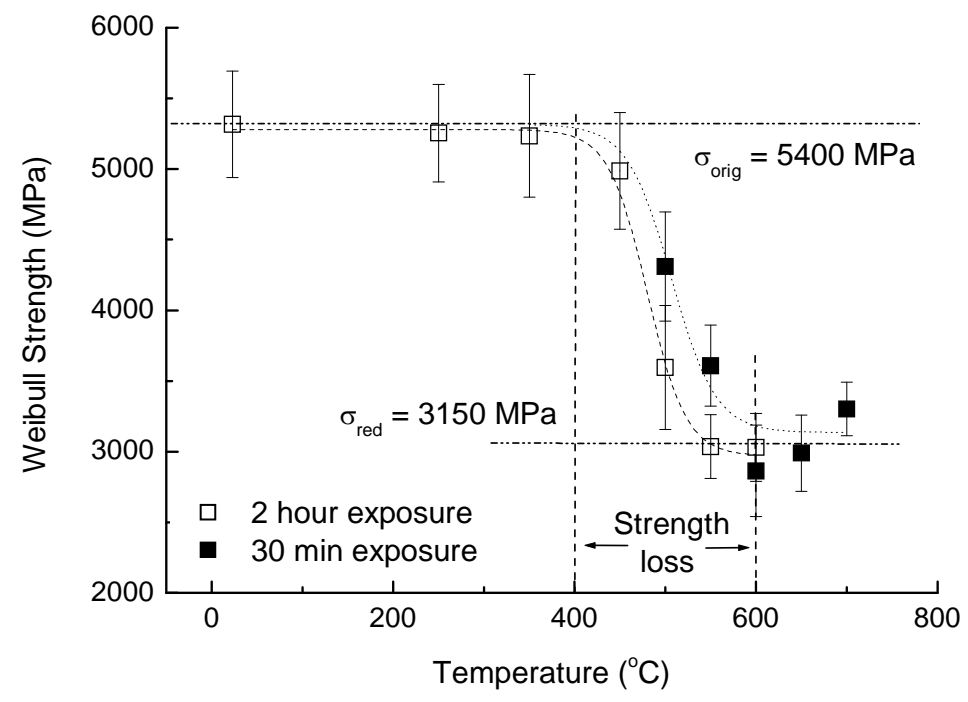


Figure 12: Estimated flaw size on fibre surface following heat-treatment in air at different temperatures.

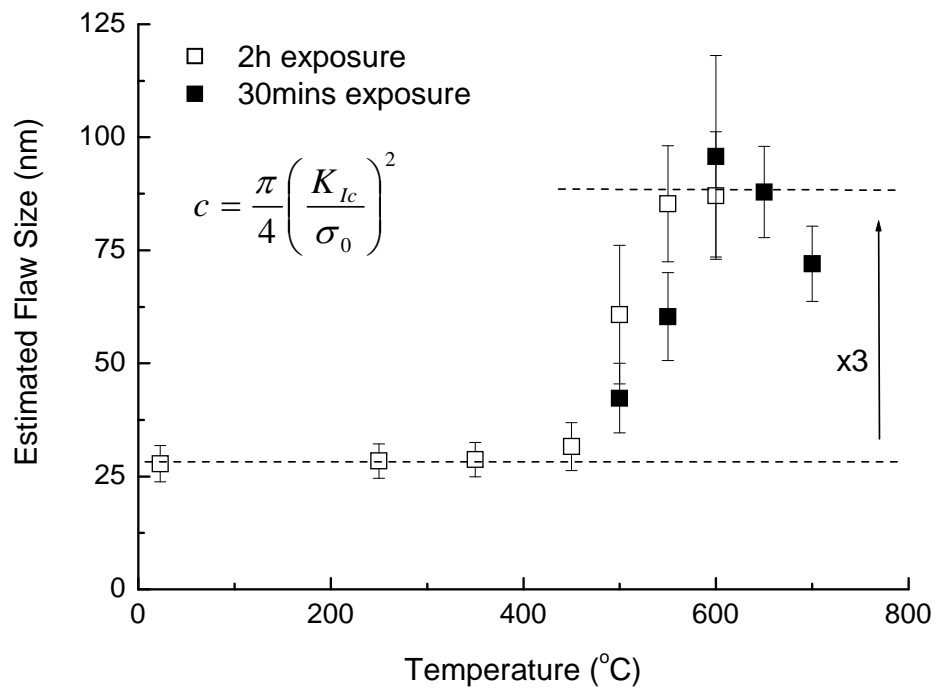

